\title{
Realism and Theories of Truth
}

\author{
Jamin Asay \\ University of Hong Kong \\ asay@hku.hk
}

Forthcoming in The Routledge Handbook of Scientific Realism, ed. Juha Saatsi

\section{Introduction}

The notion of truth has never been far from the ongoing conversation about scientific realism. Scientific realism (and its opposition) is often defined explicitly in terms of truth, and sometimes it is argued that scientific realism (and its opposition) requires a commitment to particular conceptions about the nature of truth. It's not difficult to appreciate why. The realist perspective maintains that science succeeds (or aims at succeeding) in correctly capturing the nature of reality, and to correctly describe reality just is to give a true theory about it. While it is fairly indisputable that there is some connection between truth and realism, it remains to be seen just how deep the relationship goes. In this essay, I explore some of the prominent ways that scientific realism and the theory of truth have intersected, and evaluate the arguments that have been offered concerning their relationship.

Two basic positions can be articulated when it comes to the relationship between the theory of truth and scientific realism. Those who favor neutrality believe that one's position on the theory of truth is neutral with respect to one's position on scientific realism, and vice versa. Even though realism might be defined in terms of truth, it's a further (and false) claim that realism (or its opposition) must be defined in terms of particular theories of truth. Those who favor a partisan view believe that varieties of scientific realism and anti-realism are tied up in the nature of truth, such that the former are committed to particular perspectives on truth. Of course, whether the neutral or partisan position is correct depends on precisely how one understands what realism and truth amount to, and there is no shortage of options in this regard. Still, it will be worthwhile to explore why various theorists have or have not found views about truth lurking in the debate over scientific realism.

I take up the neutral and partisan positions in turn in the following two sections. I begin by considering the case for neutrality, also offering alongside some basic remarks about the various theories of truth at issue. I then evaluate a variety of partisan positions, beginning with Arthur Fine's natural ontological attitude. I then relate Fine's views to those of major twentiethcentury partisan figures such as Thomas Kuhn, Richard Rorty, and Hilary Putnam, and finally consider some more modest, contemporary partisan views. While I do not address the related 
notions of approximate truth and truthlikeness, they are taken up by G. Schurz, "Truthlikeness and approximate truth," ch. 11 of this volume.

\section{Neutrality}

Let's begin by examining some canonical statements about scientific realism. According to Stathis Psillos's account, the realist "regards mature and predictively successful scientific theories as well-confirmed and approximately true of the world" (1999: xvii). The constructive empiricist Bas van Fraassen defines his realist opponent as one who subscribes to the thesis that "Science aims to give us, in its theories, a literally true story of what the world is like; and acceptance of a scientific theory involves the belief that it is true" (1980: 8, emphasis removed). Notice how both of these characterizations of scientific realism employ 'true'. By presenting realism as the view that science is ultimately interested in truth, Psillos and van Fraassen suggest that realists view science as a guide to learning about reality. There are facts of the matter as to what reality is like, and the job of science is to discover and describe those facts.

Anti-realist views are likewise often defined in terms of truth. Some modest forms of anti-realism maintain that science is not interested in the whole truth about reality, but just some restricted set of truths. Constructive empiricism maintains that science aims at empirical adequacy, i.e., truly describing the observable aspects of reality (see e.g. van Fraassen 1980, and also O. Bueno, "Empiricism," ch. 8 of this volume). Entity realism maintains that science is a tool for discovering the truth about what entities exist, but not facts concerning what those entities are like (see e.g. Cartwright 1983, and also M. Egg, "Entity realism," ch. 10 of this volume). Structural realists hold that science is prepared to find the truth about the structure of reality, though not its nature (see e.g. Worrall 1989, and also I. Votsis, "Structural realism and its variants," ch. 9 of this volume). More thoroughgoing forms of scientific anti-realism deliberately distance themselves from truth. Classic instrumentalism, for instance, is sometimes defined as the view that scientific theories are not even in the business of being true, or that their value and purpose is in no way related to their truth (e.g., Smart 1968). By contrast, other strong forms of scientific anti-realism, perhaps under the spell of Kuhn (1970), deny that the notion of truth makes any sense at all, and so the practice and aims of science must be understood without reference to truth at all (cf. Rorty 1972).

The central commitment of the neutral perspective is that the accounts of realism and anti-realism that employ truth in the manner described above do not thereby saddle realism and its opposition with particular views as to what truth itself is. That is to say, the aforementioned statements of realism and anti-realism can be read as not taking an explicit stand as to whether "substantive" theories of truth (such as the correspondence theory or coherence theory) or more "deflationary" theories of truth (such as disquotationalism and prosententialism) are correct. 
Substantive theories of truth take the notion of truth to be a robust one worthy of philosophical analysis. Such views aim to define truth in terms of its correspondence with reality (e.g., Newman 2002), or in terms of a kind of coherence that obtains between all the members of a particular set of propositions or beliefs (e.g., Young 2001). Deflationary theorists (e.g., Horwich 1990) find such elaborate accounts misguided, as for them the principal role for truth to play is as a kind of expressive device. The truth predicate enables us to reassert claims made by others ("What she said is true") and make simple generalizations about many claims at once ("Everything he said last month is true"). According to deflationists, when one predicates truth of, say, the sentence 'There are electrons', one is not ascribing to the sentence some complex property in need of analysis, but rather just claiming once again that there are electrons.

Important for our discussion is that the above statements of realism can be neutral with respect to the debates between substantive and deflationary theorists. For example, suppose realism is as van Fraassen maintains, and that the realist holds that in accepting a scientific theory one believes it to be true. A deflationist will point to this thesis as a paradigm instance of the utility of the truth predicate. For to say that a scientific theory is true is no more than to say that if the theory entails that aardvarks anticipate avalanches, then aardvarks anticipate avalanches, and if the theory entails that boa constrictors bustle in Bozeman, then boa constrictors bustle in Bozeman, and so on. In calling a scientific theory true, one asserts all of the implications of the theory without having to assert each one individually. What one does not do is ascribe some particular property (such as "corresponding to the facts") to the theory. Hence, what it is for a theory to be true is that, for all $p$, if the theory entails that $p$, then $p$. By rejecting substantive theories of truth, deflationists do not thereby deny that truth has some connection to scientific realism.

Likewise, there is nothing in van Fraassen's or Psillos's statements of scientific realism to disturb a substantivist about truth such as the correspondence theorist. In fact, substantivists about truth can agree with deflationists about the logical and expressive functions of 'true'. They simply go further, adding that what it is for particular implications of the theory to be true is for them to stand in a certain relation of correspondence, coherence, or what have you.

Hence, the neutralist concludes, to define realism in terms of truth is not yet to assign a specific theory of truth to any version of scientific realism or anti-realism. (See also Devitt 1984 and Horwich 1996 for more neutralist arguments.) At least, core commitments of scientific realism offer no guidance in choosing between the various substantive theories of truth and deflationary theories. That said, the stronger view that does find partisan views of truth within perspectives on the realism debate has a long history, which is the focus of the subsequent sections. 


\section{Partisanship: The Natural Ontological Attitude}

In discussing the history of realism, Putnam writes: "That one could have a theory of truth which is neutral with respect to epistemological questions, and even with respect to the great metaphysical issue of realism versus idealism, would have seemed preposterous to a nineteenth-century philosopher" (1978: 9). Indeed, the shift from idealism toward realism in the work of philosophers such as Bertrand Russell and G. E. Moore in the beginning of the twentieth century was accompanied by their eventual adoption of the correspondence theory of truth. The idealism of their forerunners went hand in hand with the coherence theories of truth (e.g., Joachim 1906).

That the debate over realism and idealism (in whatever domain) should have great implications for the theory of truth (and vice versa) is understandable when the theories of truth in question are loaded with metaphysical content and consequences. Not all views about the nature of truth are particularly metaphysical, however. Deflationary views of truth, for instance, offer positive views as to what the expressive functions of the truth predicate are, but remain silent on broader metaphysical questions such as the tenability of realism. The same holds for primitivist theories of truth (e.g., Asay 2013a). Nevertheless, some philosophers remain convinced that truth plays an indispensable role when it comes to discerning the correct metaphysical interpretation of science. This attitude has been developed quite thoroughly by Arthur Fine (1984a, 1984b, 1986). Fine, for instance, goes so far as to claim that the scientific realist "adopts a standard, model-theoretic, correspondence theory of truth" (1984a: 52), whereas the scientific anti-realist adopts a pragmatic, instrumentalist, or conventionalist theory of truth (1984b: 97).

According to Fine, there is a source of common ground between the scientific realist and anti-realist. He calls this the "natural ontological attitude" (NOA), and defines it as the acceptance of scientific theories and taking "them into one's life as true" in just the way that one accepts the evidence of one's senses (1984b: 95). Where realism and anti-realism differ is in what sort of theory they attach to 'true'. The realist accepts scientific theories as being "correspondence true", whereas the anti-realist accepts scientific theories as being "instrumentally true", or something similar. Fine's own preference is to reject both perspectives, and just accept scientific theories as being true, but without adding on top of that some theory as to what the nature of truth consists in.

Fine's presentation of the debate has an appealing structure and theoretical simplicity. But it is not at all clear that he has accurately characterized the role that truth plays in the debates over scientific realism. One common reaction to Fine's view is that he is really espousing a realist perspective, despite his claims to being above the debate and advocating "non-realism". Consider, for instance, this passage: 
When NOA counsels us to accept the results of science as true, I take it that we are to treat truth in the usual referential way, so that a sentence (or statement) is true just in case the entities referred to stand in the referred-to relations. Thus, NOA sanctions ordinary referential semantics and commits us, via truth, to the existence of the individuals, properties, relations, processes, and so forth referred to by the scientific statements that we accept as true. (1984b: 98)

It is easy for a reader of Fine to find a strong commitment to scientific realism in this passage (e.g., Musgrave 1989), as well as a strong commitment to metaphysical realism about contentious entities such as properties and relations. For one thing, some correspondence theorists of truth might recognize their own view in this statement of Fine's. What more is there to a correspondence theory of truth than a view that explicates the relationship between statements and the world via relations of reference? (See, e.g., Lynch 2009.) Correspondence theories come in a variety of forms, but at least some who carry the banner of correspondence theory are attracted to views like those that Fine is happy to accept.

Furthermore, in attributing NOA to all parties to the debate, Fine mischaracterizes many extant positions. Fine accepts that 'Electrons exist', being a consequence of contemporary physical theories, is true, and thus he is committed to the existence of electrons, to which that sentence refers. That commitment is supposed to be common ground between the realist and anti-realist (as well as Fine's non-realist). Yet it's hard to imagine many scientific anti-realists accepting this consequence, since the motivations for their view often lie precisely in being wary of ontological commitments to unobservable entities such as electrons. Van Fraassen's constructive empiricist, for instance, refuses to believe that 'Electrons exist' is true; agnosticism is the best stance regarding statements concerning the unobservable aspects of reality, even though such statements may be regarded as in fact being true or false. Other views that aim to reinterpret scientific theories so that they are not committed to unobservable entities will likewise resist NOA's plea to accept the apparent referential commitments of scientific theories.

Hence, it appears that Fine's attempt to define the debate over scientific realism fails to reflect the actual debate between realists and anti-realists. What is especially relevant for our purposes is that the disputes between, say, constructive empiricists and realists do not seem to turn at all on what theory of truth is correct. The constructive empiricist, for instance, recommends agnosticism regarding the truth or falsity of the parts of scientific theories that concern the unobservable. They thereby reject NOA, which endorses the entire truth of accepted scientific theories. But their agnosticism is not a function of their theory of truth; whatever truth itself is, constructive empiricists stay neutral as to whether what scientific theories say about the unobservable is true. Constructive empiricists may maintain their stance, regardless of whether they believe in correspondence theories of truth (to which van Fraassen seems 
sympathetic early on: see 1980: 197), deflationary theories (to which van Fraassen is currently more sympathetic: see 2008: 249), or something else. It is their epistemology that drives their agnosticism, not their theory of truth.

Fine's defense of partisanship between truth and realism faces some severe difficulties. His view predicts that realists and anti-realists alike accept in full the findings from successful scientific theorizing, and that their differences emerge only after they engage in more philosophical debates over, for example, what the best theory of truth is. As Fine might put it, philosophers don't disagree about the science itself, but rather about the best interpretation of that science. Fine, in turn, suggests offering no interpretation at all. In practice, this is not the debate that actually takes place. Theorists offer arguments about underdetermination (e.g., van Fraassen 1980), the pessimistic induction (e.g., Laudan 1981), the explanation of scientific success (e.g., Smart 1963), and so on, in order to determine whether or not we should believe in the truth of successful scientific theories. Philosophers of science engage in arguments that assess directly the metaphysical and epistemological characteristics of scientific inquiry: Does the history of science give us reason to distrust the reliability of science as a source of truth? Are the posits of scientific theories metaphysically problematic? Is it epistemologically justified to infer the existence of objects that cannot be perceived by the senses? These questions form the heart of the debate over scientific realism. Concerns about the nature of truth have not been at the forefront, and are largely irrelevant to the arguments at hand.

Why, then, does Fine put so much weight on the notion of truth in his account of scientific realism? The answer, I gather, involves the fact that Fine is responding to a philosophical tradition that has an inflated idea as to the kind of truth that realists have traditionally accepted. This conception of truth has little to do with the contemporary dialectic in the theory of truth, which often involves the debate between deflationary theories and contemporary correspondence theories. But it is a notion that has been of importance historically, especially in the mid-century metaphysical debates carried out by seminal figures such as Kuhn, Rorty, and Putnam.

\section{Partisanship: Kuhn, Rorty, and Putnam}

Kuhn's work on the history of scientific revolutions is often thought to have radical consequences for the very idea of truth, and whether scientific theories are in the business of pursuing it. On Kuhn's view, the theories generated by scientists working in different paradigms are incommensurable; they speak, in effect, different languages. As a result, there is no sense to be made of progress from one scientific paradigm to another, at least by way of being measured by their attempts to capture a true, shared picture of reality. The very idea of a shared reality, a single world described more or less accurately by successive scientific theories, is something that 
Kuhn finds objectionable. Instead of claiming that scientists from different paradigms pursue their investigations with different worldviews, Kuhn prefers to say that "after a revolution scientists work in a different world" (1970: 135). (See also H. Sankey, "Kuhn, relativism and realism," ch. 6 of this volume.)

The notion of truth plays very little role in The Structure of Scientific Revolutions, as Kuhn himself notes (1970: 170). This absence is expected, given Kuhn's skepticism about the role of truth in science. In the postscript to the second edition, Kuhn puts forward his fairly dismissive attitude about the role of truth in science:

A scientific theory is usually felt to be better than its predecessors not only in the sense that it is a better instrument for discovering and solving puzzles but also because it is somehow a better representation of what nature is really like. One often hears that successive theories grow ever closer to, or approximate more and more closely to, the truth. Apparently generalizations like that refer not to the puzzle-solutions and the concrete predictions derived from a theory but rather to its ontology, to the match, that is, between the entities with which the theory populates nature and what is "really there."

Perhaps there is some other way of salvaging the notion of 'truth' for application to whole theories, but this one will not do. There is, I think, no theory-independent way to reconstruct phrases like 'really there'; the notion of a match between the ontology of a theory and its "real" counterpart in nature now seems to me illusive in principle. (1970: 206)

What we can learn from this passage is how Kuhn understands his realist opponent. When a realist claims that a theory is true, what Kuhn hears is that the theory, in a theory-independent way, matches what is "really there". The scare quotes here are revealing. They suggest that the anti-Kuhnian uses those words in a way that Kuhn does not. Presumably, the realist has some inflated notion of 'really there' of which Kuhn is skeptical. Perhaps Kuhn's idea is that the realist thinks that there is some privileged description of the universe, and that a theory that fails to employ its terms fails to be true, despite whatever predictive successes it may enjoy. (Nowhere else in the book does Kuhn use the phrase 'theory-independent'.) If so, for Kuhn truth is essentially connected with some special vocabulary that provides the correct description of reality, whereas scientific theories are always "dependent" upon their own vocabularies which may or may not correspond to the privileged one.

To better appreciate the perspective Kuhn is endorsing, it will be worthwhile to consider the views of others who also approve of the general idea. Kuhn's claim seems to be that realism is committed to theories being "really" true in a "theory-independent" way. Such a commitment 
is too metaphysically loaded for Kuhn's tastes. Fine echoes this thought when he describes the realist as one who adds onto NOA "a desk-thumping, foot-stamping shout of "Really!" [... T] he realist wants to explain the robust sense in which be takes these claims to truth or existence, namely, as claims about reality - what is really, really the case" (1984b: 97). It might seem juvenile to joke as to whether Fine intends the realist position to be one that takes scientific theories to be really true, or one that takes scientific theories to be really, really true. But the joke has some force, since Fine crucially relies on the distinction between a theory being true and a theory being really true in order to separate his view from realism (much as Kuhn relies on distinguishing objects existing from their "really" existing). The question is what the difference is supposed to be. Fine again points to the correspondence theory of truth as the culprit. Though Fine personally takes the correspondence theory to be empty of content - it is "an arresting foot-thump and, logically speaking, of no more force" (1984b: 97) - it at least provides the needed wedge between realism on the one hand and Kuhn and Fine on the other.

The same dichotomy drawn by Kuhn and Fine also appears in the work of Richard Rorty (1972). He, too, draws a distinction between the way the realist understands truth and the world, and the way that the realists' opponent understands those notions. When discussing the idea that the world determines what is true and false (as opposed to a coherentist view that says truth is matter of coherence between beliefs, say), Rorty identifies an ambiguity. He writes: "All that "determination" comes to is that our belief that snow is white is true because snow is white, that our beliefs about the stars are true because of the way the stars are laid out, and so on" (1972: 662). This set of claims is unimpeachable, much as (on Fine's view) the commitments of NOA are. But, Rorty says, this sense of determination is not enough for the realist: "What he wants is $[\ldots]$ the notion of a world so "independent of our knowledge" that it might, for all we know, prove to contain none of the things we have always thought we were talking about" (1972: 662663). What is clear is that Rorty, like the others, portrays the realist as someone thirsting after something always elusive. For Rorty, what is distinctive about realist truth is that it could obtain in spite of everything we believe about the world being wrong. What appears to concern Rorty is the possibility (according to realism) that a scientific theory could manifest any number of empirical and practical virtues, and yet somehow fail to be true (perhaps because it fails to be couched in some privileged vocabulary).

Common among Fine, Kuhn, and Rorty is the idea that essential to scientific realism is a doctrine about truth that maintains that it "really" corresponds to the world, is "independent" of theory, and that we could in principle be wrong about it. The difficulty with pressing this line, however, is that it risks making a strawman out of the realist. After all, notice that Fine accepts that theories are true, Kuhn admits that scientific theories aim at making correct predictions, and Rorty believes that the world determines what is true. These sound like the sorts of views that realists espouse: science aims at telling a true (and not merely useful) story about the world, and 
it is the world itself (and not our beliefs and practices) that decides which theories are true or false. In order to distance themselves from the realists, Kuhn, Rorty, and Fine insert extra content into the realist view - theories aren't just true, they're really true - but at the same time they seem to suggest that this additional content isn't really additional content at all. A stomp of the foot does not add cognitive content to an utterance. That's what Fine would say, but then it's unclear why Fine thinks it's a stomp of the foot that separates his philosophical view from the realist's. The concern, ultimately, is that either these supposedly non-realist or anti-realist stances adopted by Kuhn, Fine, and Rorty are just realist perspectives after all, or that these theorists have unfairly mischaracterized the realist position.

Realists, it seems to me, have more than adequate responses to make against each of these critiques. The realist may claim that Fine's "real truth" is nothing more than truth, and so Fine needs to do more to successfully distance himself from realism. Kuhn's idea of "theory independent truth" needs some analysis that doesn't render the idea innocuous. For example, 'Kuhn is the author of The Structure of Scientific Revolutions' is true, even though some theory $\mathrm{T}_{1}$ entails it, and some theory $\mathrm{T}_{2}$ entails its negation. Kuhn is the author of The Structure of Scientific Revolutions regardless of what any theory has to say about the matter. That is a sense of theoryindependent truth the realist is quick to accept; if the realist is committed to some other notion (such as a privileged vocabulary that is indispensable for describing the "real" nature of reality), it had better be identified and explained. As for Rorty, the realist sees nothing more than a sensible epistemological fallibilism where Rorty detects grand metaphysical substance. That we might be wrong about even our most successful theories remains a possibility, however remote. The sensible realist will claim that we're not in fact wrong about the theory of evolution by natural selection, for example, but that in principle we could be mistaken about it: the evidence against the theory could forever lie beyond our ken. This unfortunate possibility is far-fetched, but a modest fallibilist epistemology acknowledges it. Rorty is mistaken to see inflated metaphysics lurking behind it.

Hilary Putnam, for his part, has articulated a similar mindset that attempts to insert a gulf between realists and anti-realists. He writes: "What I believe is that there is a notion of truth, or, more humbly, of being "right," which we use constantly and which is not at all the metaphysical realist's notion of a description which "corresponds" to the noumenal facts" (1990: 40). First notice Putnam's reluctance to even speak about truth: it's more bumble to speak of being right, and avoid appeal to 'truth' at all. Given the contemporary context in the theory of truth, this supposed humility is uncalled for. To speak of something being true need not amount to anything more than making an assertion. When I assert that it's true that Kuhn authored The Structure of Scientific Revolutions I'm only asserting that Kuhn authored The Structure of Scientific Revolutions. To think that the use of 'truth' requires any metaphysical apology is to assume from the outset that the notion is inflated. Second, we see again the common refrain that the realist is 
committed to a kind of truth that goes beyond what Putnam can accept in good conscience. Putnam invokes Kant's phenomena/noumena distinction, which is a clue as to what Kuhn, Fine, and Rorty may also suspect is distinctive about realism. Non-realists, they say, can accept that truth is correspondence to reality in some sense, but not in the distinctly realist sense of truth as correspondence to noumenal reality (or the "World", as Fine (1986) writes with italics and a capital 'w').

I am skeptical that scientific realists rely on this Kantian distinction in developing their view (see also Musgrave 1989). The distinction plays no role in Psillos's defense of realism, and for all of van Fraassen's talk of "saving the phenomena", The Scientific Image never once discusses the noumena. Perhaps, though, there is a way of articulating the basic thought around which Putnam and the others seem to be circling, drawing on the idea of a "privileged language" from above. Imagine that there is some language - distinct from any extant natural language - that "carves nature at the joints". That is to say, all of the predicates of this language refer to the genuine, natural properties of the world (as opposed to gerrymandered properties like grue). The other features of the language - its quantifiers and connectives, for example - also map onto the genuine structure of the world. This language may be used to describe the world "as it really is", in a way that our humble natural languages that are overly concerned with the more derivative parts of reality never could. This is the language of God, or the language of "the book of the world". Facts expressed in this language are the noumenal facts. Sure, it's true that Kuhn authored The Structure of Scientific Revolutions. But presumably, that claim reduces down to some complicated set of facts of microphysics that can be expressed using the privileged language: those are the really true facts, the ones about quarks and charms, not about men and monographs. That there is such a description of the world, and that science aims at it, is the distinctive commitment of realism.

If this sort of picture is what the partisan opponents have in mind when they speak of "real", "theory independent", or "noumenal" truth, I again wonder on behalf of scientific realists as to whether this is a necessary component of the latter's view. To be sure, the account has its defenders, Ted Sider (2011) being a prominent recent example. Yet it is hardly necessary for articulating the kind of perspective on science that realists usually defend. The joint-carving view is a broader metaphysical perspective one might have, but it's one that reaches far beyond the interests of the scientific realism debates and extends into the canonical discussions about metaphysics, empiricism, transcendental idealism, and the like. These are perennial philosophical topics of great interest, but to see them as essential to capturing the basic perspective of the scientific realist is to inflate the view beyond what's warranted. The partisans, it seems, are guiltier of inflating scientific realism than are realists of inflating truth.

Summing up, the defenders of the partisan perspective on truth and realism - at least those coming to the issue from the non-realist camp - assign to scientific realism a conception 
of truth that is thoroughly metaphysical and involves a commitment to views that speak to a host of grand philosophical questions such as the tenability of transcendental idealism and the like. The non-realists appear to take this tack because it allows them to embrace the truth of scientific theories while disavowing the realist position: Yes, scientific theories are true of course. What means do we have of discovering the truth about the world better than science? But whether or not they're "really true" or describe "the $W$ orld" in all its noumenal glory are questions that either escape our grasp, are empty, or don't even make sense. What's revealing about this conception of the debate is that it's coming from the non-realist camp; as a result, we should be wary of thinking that they have correctly described their opponents' positions. When the only option you leave open to your opposition is that their view is meaningless, empty, or entails skepticism, there is cause for re-evaluation, and concern that you have erected a strawman.

In the face of this sort of realist retort - ordinary truth itself is the realist's standard for science, not "joint carving in the language of God noumenal truth" - the partisan opponents worry that realism is reduced to triviality or banality (cf. Rorty 1986: 354 and Putnam 1990: 32). Who would deny that scientific theories are true (even if they're not a source of God's-eye perspective truth)? Well, plenty of those deeply engaged in the realism debate. Worrall (1989) doubts science's ability to teach us the truth about the nature of light. Van Fraassen believes that scientific investigation gives us no evidence as to the existence of DNA molecules and electrons (1980). Laudan argues that the history of science shows that we ought to be skeptical about even the best of our current theories (1981). None of these views accepts that we should blithely commit to the truth of our best science; furthermore, they do this independently of offering philosophically loaded conceptions of truth. If committing to the truth of theories automatically involved such an inflated (or at least highly controversial) metaphysical worldview, then there would be independent reason to pause before accepting the truth of our best science. But what the actual practitioners in the philosophy of science demonstrate is that even if we commit to a fully deflationary conception of truth, there is still reason to be cautious about accepting the truth of scientific theories. Truth - even when brought back down to earth from noumenal heaven is still a major commitment, and one to which many philosophers of science object. If the nonrealist partisans are happy to commit to it nonetheless, that highly suggests that they should be interpreted as reluctant realists.

\section{Modest Partisanship}

The partisan views discussed above have all come from those who reject the label of scientific realism. In effect, I have argued that their criticisms are better directed at those who, like Sider, embrace a particularly loaded (i.e., joint-carving) broader metaphysical outlook.

Defenders of scientific realism endorse a more modest thesis that need not take a stand on some 
of the grander philosophical questions of metaphysics. In this section, I address some more contemporary perspectives on truth and realism that don't infuse the issue with such imposing philosophical implications, and yet still find a substantive role for truth to play in the understanding of science and its success.

Philip Kitcher (2002) has defended what he calls a "modest correspondence theory of truth", which he more or less equates with the basic commitment of scientific realism (or at least his brand of realism). Kitcher's modest theory "doesn't suppose that there are entities, facts, to which true sentences correspond" (2002: 347). Nor, presumably, does Kitcher's realist employ the even grander metaphysical theses adumbrated by the partisans of the previous sections. Kitcher's positive account of truth maintains that truths are about objects that exist independently of those who make utterances concerning them, and that a causal theory of reference is required to explain how linguistic tokens represent mind-independent objects. It is the second of these commitments that Kitcher believes separates his modest realist and correspondence theorist from the deflationist. The adoption of this causal theory of reference is useful to the realist because it buttresses the classic realist argument that truth offers the best explanation of ordinary and scientific success, both practical and theoretical. Truth can explain success because a theory being true means that there are causal connections between how the world is and how the theory represents the world. Maps, by analogy, are successful when they stand in the right causal relationships to the part of the world that they claim to model.

All told, Kitcher identifies scientific realism as the view that many of the well-established claims made by science are true in the sense offered by his modest correspondence theory of truth. There is reason to adopt realism in this sense because the kind of truth (and, importantly, reference) posited by the view is essential for explaining the many successes of mature science. Here we find a kind of partisanship - which theory of truth you maintain makes a difference as to what view on realism is most tenable - albeit one that is not so burdened with the metaphysical extravagances of the past. Still, Kitcher's presentation faces its own challenges. Notably, Kitcher defines deflationism about truth in terms of a thesis about reference: that all there is to say about reference are sentences of the form ' $a$ ' refers to a, if a exists'. This thesis is best thought of as a deflationary view about reference, and so is separable from deflationary views about truth. It's true that Paul Horwich (perhaps the most ardent defender of deflationism) endorses both (1990: 121), but that is not to say that the two views are the same, or that one entails the other. For example, one might adopt a causal story about how 'Kuhn' has come to refer to Kuhn, and how 'The Structure of Scientific Revolutions' has come to refer to The Structure of Scientific Revolutions. The proponent of that account about reference could still maintain that there is no substantial property in virtue of which 'Kuhn is the author of The Structure of Scientific Revolutions' is true. There is nothing more to the sentence being true than Kuhn being the author of the book. The upshot for Kitcher is that while realism might be aided by a partisan view on 
reference, truth ultimately has nothing to do with it.

Other modest takes on partisanship might, like Kitcher's, try to find some room for how the theory of truth can lead to progress in the discussion of scientific realism. Stephen Leeds (2007) considers (and rejects) some possible avenues down which realists might venture. His view, with which I am sympathetic, is that deflationary views are perfectly sufficient for the tasks scientific realists take up. To defend partisanship, theorists need to come up with some task for a substantive theory of truth to perform that deflationism cannot handle. See, for instance, Jarrett Leplin's argument for why a deflationary "redundancy" theory can't capture the necessary explanatory import of truth needed for realism (1997: 17-19).

\section{Conclusion}

The central questions about the relationship between truth and realism are (1) does truth figure into the definition of scientific realism, and (2) are particular views about truth necessary to the debate over scientific realism? I have suggested a positive answer to the first question, and presented a number of difficulties for positive answers to the second. Crucial to the realist position is that science succeeds (or aims to succeed) at discovering the (approximate) truth about reality, though it may be indifferent as to whether the correct theory of truth is offered by correspondence or deflationary theories. Whether realism is exhausted by its relationship to truth is another matter. I have argued elsewhere, for instance, that realists need to commit not just to the (approximate) truth of scientific theories, but also to some sort of mind-independent reality of unobservable objects that grounds the truth of scientific theories (Asay 2013b). Otherwise, a phenomenalist view that accepts that scientific theories are true, but made true exclusively by a realm of sense data would qualify as a realist theory. (Van Fraassen speaks to such concerns by requiring that theories be literally true, but I take the issue to be a metaphysical one, not a semantic one.)

Given the sheer number of different theories that have been defended in the name of scientific realism, the correspondence theory of truth, and others, it is inevitable that some theorists will develop theories about realism and truth that are necessarily connected; Kitcher provides just one example. Nevertheless, it remains plausible that though truth and realism are intimately connected, realism need not adopt a stance on what exactly truth is. That may come as a shock to those with nineteenth-century sensibilities, but times have changed. And for the better: neutrality is the preferred view, methodologically speaking, as it allows us to develop views with little risk of begging the question against other, potentially quite different views on other, distinct matters. 


\section{References}

Asay, J. (2013a) The Primitivist Theory of Truth. Cambridge: Cambridge University Press.

_ (2013b) “Three paradigms of scientific realism: a truthmaking account," International Studies in the Philosophy of Science 27, 1-21.

Cartwright, N. (1983) How the Laws of Physics Lie. Oxford: Clarendon Press.

Devitt, M. (1984) Realism and Truth. Princeton: Princeton University Press.

Fine, A. (1984a) “And not anti-realism either," Noûs 18, 51-65.

_ (1984b) "The natural ontological attitude," in J. Leplin (ed.), Scientific Realism, pp. 83-107.

Berkeley: University of California Press.

_ (1986) "Unnatural attitudes: realist and instrumentalist attachments to science," Mind 95, 149-179.

Horwich, P. (1990) Truth. Oxford: Basil Blackwell.

_ (1996) "Realism and truth," Philosophical Perspectives 10, 187-197.

Joachim, H. H. (1906) The Nature of Truth. Oxford: Clarendon Press.

Kitcher, P. (2002) "On the explanatory role of correspondence truth," Philosopby and Phenomenological Research 64, 346-364.

Kuhn, T. S. (1970) The Structure of Scientific Revolutions (2nd ed.). Chicago: University of Chicago Press.

Laudan, L. (1981) “A confutation of convergent realism,” Philosophy of Science 48, 19-49.

Leeds, S. (2007) "Correspondence truth and scientific realism," Synthese 159, 1-21.

Leplin, J. (1997) A Novel Defense of Scientific Realism. New York: Oxford University Press.

Lynch, M. P. (2009) Truth as One and Many. Oxford: Clarendon Press.

Musgrave, A. (1989) “NOA's ark-Fine for realism," Philosophical Quarterly 39, 383-398.

Newman, A. (2002) The Correspondence Theory of Truth: An Essay on the Metaphysics of Predication. Cambridge: Cambridge University Press.

Psillos, S. (1999) Scientific Realism: How Science Tracks Truth. London: Routledge.

Putnam, H. (1978) Meaning and the Moral Sciences. Boston: Routledge and Kegan Paul.

_ (1990) A defense of internal realism. In his Realism with a Human Face, ed. James Conant, pp. 30-42. Cambridge: Harvard University Press.

Rorty, R. (1972) “The world well lost," Journal of Philosophy 69, 649-665.

_ (1986) "Pragmatism, Davidson and truth," in E. LePore (ed.), Truth and Interpretation:

Perspectives on the Philosophy of Donald Davidson, pp. 333-55. Oxford: Basil Blackwell.

Sider, T. (2011) Writing the Book of the World. Oxford: Clarendon Press.

Smart, J. J. C. (1963) Philosophy and Scientific Realism. London: Routledge and Kegan Paul.

— (1968) Between Science and Philosophy. New York: Random House.

van Fraassen, B. C. (1980) The Scientific Image. Oxford: Clarendon Press. 
(2008) Scientific Representation: Paradoxes of Perspective. Oxford: Clarendon Press.

Worrall, J. (1989) “Structural realism: the best of both worlds?”, Dialectica 43, 99-124.

Young, J. O. (2001) "A defence of the coherence theory of truth," Journal of Philosophical Research 26, 89-101. 